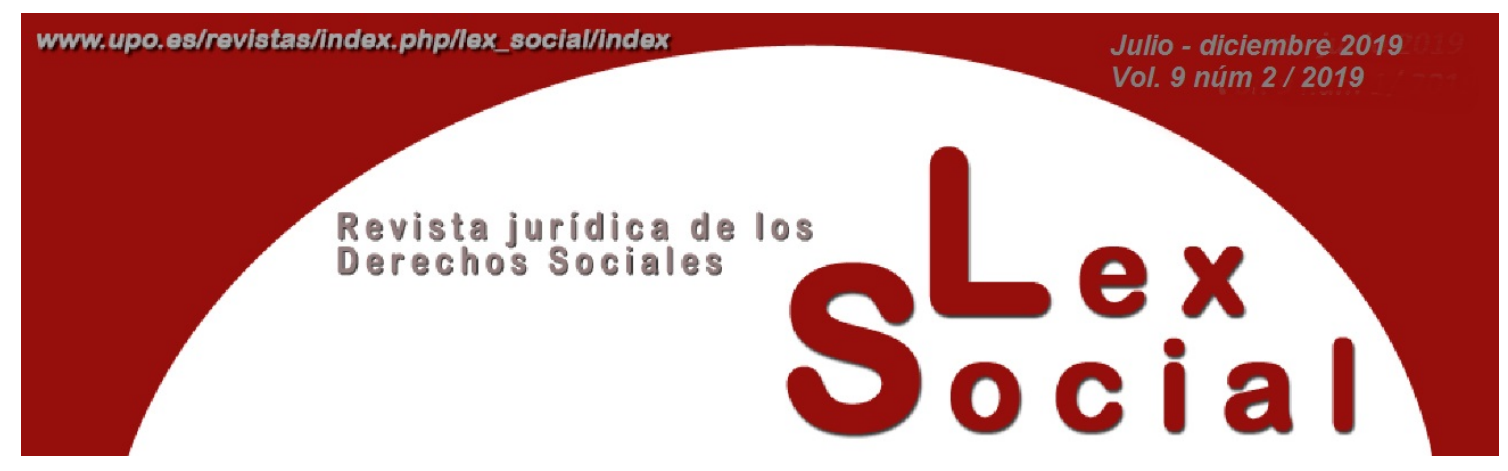

\title{
PROFESIONALIZACIÓN EFECTIVA DEL SERVICIO DOMÉSTICO. UN TRABAJO PENDIENTE
}

\section{EFFECTIVE DOMESTIC SERVICE PROFESSIONALIZATION. A PENDING JOB}

CONCEPCIÓN SANZ SÁEZ

Profesora Asociada Doctora Derecho del Trabajo y Seguridad Social

Universidad de Castilla La Mancha, Ciudad Real ${ }^{1}$

\section{RESUMEN}

En la actualidad aún seguimos notando una tendencia maternalista y servilista hacia los problemas del servicio doméstico, por lo que para mejorar las condiciones laborales y de protección social en este sector hace falta profesionalizar las actividades que realizan, así como que el gobierno se involucre a distintos niveles, para dar respuesta a esta necesidad, como podría ser la ratificación del Convenio 189 de la Organización Internacional del Trabajo, además de sensibilizar a la parte empleadora al respecto.

Palabras clave: Servicio doméstico, profesionalización, capacitación, cualificación, acreditación profesional

\section{Abstract}

We are currently still noticing a maternalist and servilista trend towards domestic problems, so to improve the working conditions and social protection in this sector need to professionalise activities carried out in domestic service, as well as that the Government be involved at different levels, to respond to this need, such as the

\footnotetext{
${ }^{1}$ Funcionaria en la Dirección Provincial de la TGSS de Ciudad Real
} 
ratification of the Convention 189 of the of the ILO, as well as sensitize the employers to the connection.

KEYWORDS: Domestic service, professionalism, training, qualifications, professional accreditation

SUMARIO

1. CUESTIONES GENERALES

2. DIRECTRICES COMUNITARIAS EN LA MATERIA

3. ESPECIAL ATENCIÓN AL COLECTIVO DE TRABAJADORES EN SITUACIÓN DE RIESGO DE EXCLUSIÓN SOCIAL Y LABORAL

4. LA FORMACIÓN PROFESIONAL COMO ELEMENTO CLAVE EN EL NUEVO ESTATUTO JURÍDICO

5. LA PROFESIONALIDAD COMO ELEMENTO SUSTANTIVO EN LA PRESTACIÓN DEL TRABAJO DOMÉSTICO

5.1 LA CAPACITACIÓN COMO FACTOR MODULADOR DE LA PROFESIONALIDAD DEL TRABAJADOR

5.2 LA ADQUISICIÓN DEL CERTIFICADO DE PROFESIONALIDAD Y LOS ESTÁNDARES DE CALIDAD EN LA PRESENTACIÓN DEL SERVICIO DOMÉSTICO

5.3 EL OBJETIVO DEL RECONOCIMIENTO DE LAS CUALIFICACIONES PROFESIONALES COMO FACTOR DETERMINANTE EN LA MEJORA DE PRESTACIÓN DEL SERVICIO

5.4 LA AUSENCIA DE RECONOCIMIENTO DE CUALIFICACIÓN Y ACREDITACIÓN PROFESIONAL EN CONSONANCIA CON SU TRABAJO EN EL SECTOR ANALIZADO

5.4.1 EL CATALOGO NACIONAL DE CUALIFICACIONES PROFESIONALES Y SU RELACIÓN CON EL SECTOR ESTUDIADO

5.4.2 EL SISTEMA DE CUALIFICACIONES Y SU RELACIÓN CON EL SECTOR ESTUDIADO

5.5 LAS NORMAS DE COMPETENCIAS Y SU INCIDENCIA EN EL NUEVO PERFIL PROFESIONAL DE LAS EMPLEADAS DE HOGAR

5.5.1 DELIMITACIÓN DEL NECESARIO PERFIL DE COMPETENCIAS EN ESTE SECTOR 6. CONCLUSIONES Y PROPUESTAS 


\section{CUESTIONES GENERALES}

Como todos sabemos, el empleo en el hogar, se sitúa a caballo entre el ámbito laboral, al cumplir los requisitos necesarios, y el ámbito privado al realizarse en un hogar familiar.

La convivencia tan directa entre personas empleadas y empleadoras, en un ambiente tan privado como es el hogar, a menudo genera lazos afectivos que hacen que el trabajo en este sector, sea concebido como algo más cercano a lo privado y personal, que a lo profesional, provocando una relación laboral ambigua y negando al trabajo desempeñado el status de "trabajo profesional", con la descripción de competencias y capacidades requeridas para el desempeño de ésta ocupación, así como sus condiciones de desarrollo técnico, lo que propicia intromisiones, abusos y exigencias por la parte empleadora al margen de lo pactado, de la misma manera, en ocasiones, falta de capacitación por la parte de la trabajadora.

Ante esta falta de objetivación, debemos plantearnos la necesidad de profesionalizar y mejorar la regulación laboral del sector, con la finalidad de evitar las condiciones de arbitrariedad en que se sujeta actualmente dicha ocupación.

\section{DIRECTRICES COMUNITARIAS EN LA MATERIA}

La Unión Europea, en el marco de un conjunto de iniciativas para lograr la transparencia de las cualificaciones de los trabajadores de los Estados Miembros y un espacio europeo del aprendizaje permanente, ha impulsado la evolución de los sistemas de educación y formación profesional de sus integrantes hacia sistemas inspirados en catálogos de cualificaciones profesionales.

De este modo, las políticas y programas de formación profesional continua deberían tener por objetivo "mejorar la aptitud del individuo de comprender su medio de trabajo y el medio social y de influir, individual o colectivamente, sobre estos" (artículo $1^{\circ}$ num. 4 del Convenio Internacional del Trabajo $\mathrm{N}^{\mathrm{o}} 142$ ), igualmente se deben tener "presentes al mismo tiempo las necesidades de la sociedad" (artículo. $1^{0}$ num.5 del mismo CIT $\mathrm{N}^{\circ}$ 142). Teniendo en cuenta los antecedentes de nivel internacional en estas cuestiones y la tendencia creciente a considerar a la Formación Profesional y al saber del trabajador como un componente del potencial productivo de una sociedad, resulta inaplazable definir a la formación, a sus condiciones de cumplimiento y a las obligaciones y derechos de ella devenidos como una materia negociable. En este sentido, procede ampliar esta breve descripción de antecedentes jurídicos que dan soporte a la negociación colectiva en materia de formación.

\footnotetext{
${ }^{2}$ Según la Ley Orgánica 5/2002 de 19 de junio, de las Cualificaciones y de la Formación Profesional. BOE núm. 47, de 20 de junio de 2002 es un "conjunto de competencias profesionales con significación en el empleo que pueden ser adquiridas mediante formación modular u otros tipos de formación, así como a través de la experiencia laboral".
} 
Para ello, rescatar la Resolución de la Conferencia General de la OIT sobre el desarrollo de recursos humanos (88a reunión, año 2000) que es todavía más explícita en el sentido de la utilidad social de la formación, cuando dice: "La economía y la sociedad en general, de la misma manera que las personas y las empresas, se benefician de la formación y desarrollo de recursos humanos. La economía es más productiva, innovadora y competitiva gracias a la existencia de un potencial humano más calificado. La formación y desarrollo de recursos humanos ponen de relieve los valores fundamentales de una sociedad de equidad, justicia, igualdad de trato entre hombres y mujeres, no discriminación, responsabilidad social y participación”.

Las principales iniciativas en éste sentido son el Sistema Europeo de Transferencia y Acumulación de Créditos ${ }^{3}$, la Declaración de Copenhague, de 30 de noviembre de 2002, sobre una mejor cooperación europea en materia de formación y enseñanza profesional $^{4}$, para aumentar la transparencia en la formación y en la enseñanza profesional, que consideró como prioridades principales, entre otras, la propagación de herramientas y redes de información que integraran en un solo marco los instrumentos ya existentes (curriculum vitae europeo, suplementos a los certificados o diplomas, el marco común de referencia de los idiomas y Europass ${ }^{5}$ ).

En relación con tal agrupamiento, se hacía necesario reforzar los sistemas de información, orientación y asesoramiento a los Estados Miembros sobre el acceso a los niveles de enseñanza y formación, y al empleo. Más específicamente, se propuso el desarrollo de principios comunes de validación del aprendizaje formal y no formal, los principios europeos para la identificación y la validación del aprendizaje no formal e informal $^{6}$, así como el Marco Europeo de Cualificaciones para el aprendizaje

\footnotetext{
${ }^{3}$ ECTS es el Sistema de Transferencia y Acumulación de Créditos de la Unión Europea con el fin de establecer procedimientos comunes que garanticen el reconocimiento académico de los estudios realizados en el extranjero. Con este fin, proporciona un sistema de evaluación y comparación de estudios, así como de transferencia de éstos de una institución a otra.

${ }^{4}$ http://www.mec.es/educa/sistema-

educativo/eadul/files/declaracioncopenhague.pdf\#search=\%22Declaraci\%C3\%B3n\%20de\%20los\%20Mi nistros\%20Europeos\%20de\%20Formaci\%C3\%B3n\%20y\%20Ense\%C3\%B1anza\%20Profesional\%20y\% 20la\%20Comisi\%C3\%B3n\%20Europea\%2C\%20reunidos\%20en20Copenhague\%20los\%20d\%C3\%ADa s\%2029\%20y\%2030\%20de\%20noviembre\%20de\%202002\%22). (Consultado el 12/01/2019).

${ }^{5}$ Es un expediente personal y coordinado de cinco documentos, que los ciudadanos podrán utilizar con carácter voluntario para comunicar y presentar de manera clara y sencilla las aptitudes, las titulaciones y certificaciones adquiridas a lo largo de la vida en toda Europa (Unión Europea, Área Económica de Libre Comercio, Espacio Económico Europeo y los Países Candidatos), siempre que se desee buscar trabajo o solicitar la admisión en algún programa educativo o formativo, como vemos, su objetivo principal es ayudar a los ciudadanos a presentar sus capacidades y cualificaciones de manera eficaz para encontrar trabajo o formación.

${ }^{6}$ La revista Comparative Education ha dedicado un número especial a las políticas europeas de formación profesional, algunos de cuyos artículos abordan la situación actual de estos programas y realizan propuestas. Por ejemplo: ERTL, 2006: 5-27; ERTL, H. y PHILLIPS, D. "Standardization in EU education and training policy: findings from a European research network”. Comparative Education, 42 (1),2006. págs. 77-91.
} 
permanente y la recomendación relativa a la creación del Sistema Europeo de Créditos para la Educación y la Formación Profesional (ECVET ${ }^{7}$ ).

La propia OIT, en la Recomendación 195 de 2004, aconseja a sus miembros el desarrollo de "marcos nacionales de cualificaciones", como instrumento para facilitar el aprendizaje permanente, el ajuste de la oferta y demanda de competencias en el mercado de trabajo, todo ello, para facilitar el reconocimiento de las competencias adquiridas a lo largo de la vida laboral.

En éste sentido, una norma comunitaria de obligada referencia, que entendemos debe incorporarse en este apartado, es la Directiva 2005/36/CE del Parlamento Europeo de 7 de septiembre de 2005 relativa al reconocimiento de cualificaciones profesionales que, sustituyendo a varias Directivas anteriores ${ }^{8}$, establece las normas de reconocimiento entre los Estados miembros de las profesiones reguladas. Aunque es independiente del European Qualification Framework (EQF), en ella se definen las cualificaciones profesionales como "las cualificaciones acreditadas por un título de formación, un certificado de competencia, o una experiencia profesional”, y los títulos de formación como “... los diplomas, certificados y otros títulos expedidos por una autoridad de un Estado miembro (...) que sancionan una formación profesional

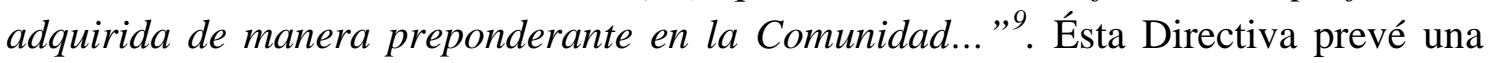
simplificación y una mejora del sistema de cualificaciones profesionales, promoviendo una flexible prestación de servicios y del derecho de establecimiento dentro del mercado interior, y manteniendo al mismo tiempo el indispensable control para la protección de los consumidores, de la salud y del interés público. Es la primera modernización global del sistema comunitario de reconocimiento de cualificaciones profesionales, mantiene por tanto el mecanismo de reconocimiento establecido por las Directivas 89/48/CEE y 92/51/CEE y el mecanismo de reconocimiento automático de títulos establecido por las Directivas sectoriales en las profesiones de médico, enfermero responsable de cuidados generales, odontólogo, veterinario, matrona o asistente obstétrico, farmacéutico y arquitecto.

Una definición más amplia de este concepto, que ejemplifica sus múltiples ramificaciones, la propone la Unión Europea " ${ }^{10}$ "Una cualificación es alcanzada cuando

\footnotetext{
${ }^{7}$ European Credit Transfer System for Vocational Education and Training.

${ }^{8}$ Deroga las Directivas 99/42, de 7 de junio (Ref. DOUE-L-1999-81596), 93/16, de 5 de abril (Ref. DOUE-L-1993-81081), 92/51, de 18 de junio (Ref. DOUE-L-1992-81212), 89/48, de 21 de diciembre de 1988 (Ref. DOUE-L-1989-81706), 85/433, de 16 de septiembre (Ref. DOUE-L-1985-80782), 85/432, de 16 de septiembre (Ref. DOUE-L-1985-80781), 85/384, de 20 de junio (Ref. DOUE-L-1985-80700), 80/155, de 21 de enero (Ref. DOUE-L-1980-80028), 80/154, de 21 de enero (Ref. DOUE-L-1980-80027), 78/1027, de 18 de diciembre (Ref. DOUE-L-1978-80415), 78/1026, de 18 de diciembre (Ref. DOUE-L1978-80414), 78/687, de 25 de julio (Ref. DOUE-L-1978-80274), 78/686, de 25 de julio (Ref. DOUE-L1978-80273), 77/453, de 27 de junio (Ref. DOUE-L-1977-80175), 77/452, de 27 de junio (Ref. DOUE-L1977-80174).

${ }^{9}$ Directiva del Parlamento Europeo de septiembre de 2005 art. 3b y c.

${ }^{10}$ Towards a european qualification framework for lifelong learning, Commission of the European Communities, Bruselas, 2005.
} 
un organismo competente determina que el aprendizaje de un individuo ha alcanzado un cierto estándar de conocimiento, habilidades y competencias. El estándar de aprendizaje logrado es confirmado por medios como el proceso de evaluación o la culminación exitosa de un curso. El aprendizaje y la evaluación para una cualificación pueden tener lugar a través de un programa de estudio o en el puesto de trabajo."11. Esta definición insiste en el valor de la cualificación en el mercado de trabajo y en que esta puede dar derecho legalmente a practicar un oficio. Tomando en cuenta todas estas consideraciones, el principal objetivo de la Unión Europea parece ser la consolidación de las divergentes medidas legislativas para alcanzar una mayor liberalización en las libertades de prestación de servicios y de establecimiento, para desarrollar acuerdos entre los sectores públicos y privados a través de cuerpos profesionales, y para dotar a las autoridades nacionales de un mayor papel central en el desempeño de sus funciones, lo que supone un paso más hacia la liberalización y la consecución de un mercado interior sin fronteras interiores en el contexto de la Unión Europea, especialmente después del proceso de ampliación, en el que la armonización legislativa es un necesario instrumento para su consecución.

De este modo, la competencia vendría a ser la característica, el conjunto de atributos que la persona posee o desarrolla, entre tanto la cualificación sería el reconocimiento formal, esto es, acoplado en una institucionalidad que le garantiza atributos de legitimidad, calidad y transparencia. La acumulación de competencias a lo largo de la vida requiere de un sistema transparente de reconocimiento de los logros educativos en términos de cualificaciones ${ }^{12}$.

\section{ESPECIAL ATENCIÓN AL COLECTIVO DE TRABAJADORES EN SITUACIÓN DE RIESGO DE EXCLUSIÓN SOCIAL Y LABORAL}

Dentro del espacio europeo, y en el contexto de los nuevos objetivos planteados en el Consejo de Lisboa de marzo del año $2000^{13}$, requieren una especial atención los colectivos de trabajadores que se encuentran en situación de mayor riesgo de exclusión social y laboral, al presentar éstos más dificultades para adaptarse a las continuas demandas del mercado de trabajo y, por tanto, para lograr su inserción laboral y el mantenimiento en el puesto de trabajo.

\footnotetext{
${ }^{11}$ Por su parte la Organización Internacional del Trabajo (1993) define el concepto de Competencia Profesional "como la idoneidad para realizar una tarea o desempeñar un puesto de trabajo eficazmente por poseer las calificaciones requeridas para ello. En este caso, los conceptos competencia y calificación, se asocian fuertemente dado que la calificación se considera una capacidad adquirida para realizar un trabajo o desempeñar un puesto de trabajo".

${ }^{12}$ DE LA FUENTE, J. "Estrategias metodológicas y de evaluación para promover la competencia para aprender a aprender”. Aula de Innovación Educativa n 192 (junio 2010), págs. 11-14.

${ }^{13}$ Consejo Europeo de Lisboa. 23 y 24 de marzo 2000. Conclusiones de la Presidencia. Disponible en http://www.europarl.europa.eu/summits/lis1_es.htm (consultado el 20/02/2019).
} 
Entre estos colectivos, se encuentra el conformado por las trabajadoras y los trabajadores con bajo nivel de cualificación ${ }^{14}$, que según el Instituto Nacional de las Cualificaciones (INCUAL) ${ }^{15}$, son aquellos que poseen competencias en un conjunto reducido de actividades relativamente simples, siendo sus conocimientos teóricos y capacidades prácticas limitados, para cuya situación se estima, además, un empeoramiento si tenemos en cuenta las previsiones del Centro Europeo para el Desarrollo de la Formación Profesional (CEDEFOP) ${ }^{16}$, según las cuales, para el año 2020 "Ia demanda de trabajadores de baja cualificación en Europa se reducirá en unos 12 millones”, cayendo del 20\% actual al 15\% los empleos destinados a éstos. Por tanto, se hace necesaria una adecuada intervención en materia de formación para estas trabajadoras y trabajadores, de forma que puedan lograr un mayor desarrollo de sus competencias, tanto transversales como específicas, de forma que sea posible mejorar su cualificación reduciendo así su situación riesgo ${ }^{17}$.

Las necesidades de formación están diferenciadas en función de la nacionalidad, cultura o procedencia ${ }^{18}$. Porque como se sabe, este colectivo está constituido cada vez más por un mayor número de inmigrantes ${ }^{19}$.

\footnotetext{
${ }^{14}$ Real Decreto 395/2007, de 23 de marzo, por el que se regula el subsistema de formación profesional para el empleo. BOE núm. 87, de 11 de abril de 2007. ALALUF, M. "La cualificación: ¿de qué se está hablando?”. Revista Europea de Formación Profesional, nº 2. págs. 33-36.

${ }^{15}$ Para delimitar el perfil de los trabajadores de bajo nivel de cualificación se utilizó el Catálogo Nacional de Cualificaciones Profesionales. Concretamente, se seleccionaron las cualificaciones detalladas en la Tabla ED1 y se tomaron como referencia las ocupaciones que se muestran.

Cualificaciones Profesionales Seleccionadas (nivel 1). Ocupaciones incluidas (Las ocupaciones Asistente y cuidador de niños, Asistente y cuidador de mayores y Asistente y cuidador de personas con discapacidad se añadieron como ocupaciones propias de la cualificación, tras considerar lo establecido en el artículo 1.4 del Real Decreto 1424/85, que regulaba la relación del Servicio del Hogar Familiar. BOE núm. 193, de 13 de agosto de 1985.)

- Empleo Doméstico

- Limpiador/a doméstico/a.

- Cocinero/a doméstico/a.

- Planchador/a doméstico/a.

- Empleado/a de hogar.- Asistente y cuidador /a de niños.

- Asistente y cuidador/a de mayores.

- Asistente y cuidador/a de personas con discapacidad. Cualificaciones y ocupaciones seleccionadas tomadas de la Familia Profesional Servicios Socioculturales y a la Comunidad.

${ }^{16}$ Centro europeo para el Desarrollo de la Formación Profesional (CEDEFOP). Febrero de 2010. Nota Informativa. El empleo en Europa exigirá más conocimientos y competencias. Europa tiene que aprovechar mejor su potencial humano. ISSN 1831-2446. Disponible en http://www.cedefop.europa.eu/EN/Files/9021_es.pdf (consultado el 20/02/2019).

17 ALEX, L. (1991). "Descripción y registro de las cualificaciones". Revista Europea de Formación Profesional, no 2. CEDEFOP, Berlín, págs. 23-27.

${ }^{18}$ DE LUCAS, J., “¿Elogio de Babel? Sobre las dificultades del Derecho frente al proyecto intercultural”. ACFS, n³1, 1994, págs.15-39.

${ }^{19}$ Dada la situación de irregularidad de una gran parte de estas personas, especialmente entre la población inmigrante, resulta difícil disponer de datos acerca del número de cuidadores y cuidadoras empleados para el cuidado de personas dependientes. Sin embargo, según diferentes estudios en GALLART FERNÁNDEZ-PUEBLA, A., Sobrecarga del cuidador inmigrante no profesional formal en Barcelona. Ed. Universitat Internacional de Catalunya, 2007. Instituto de la Mujer: Cuidados a personas dependientes prestados por mujeres: valoración económica, 2008 y el propio Libro Blanco de la Dependencia
} 
La Ley Orgánica 5/2002, de 19 de junio ${ }^{20}$, junto con las órdenes de creación de los distintos institutos autonómicos de las cualificaciones y de institución de las cualificaciones profesionales, dan sustento legal a este interés por el concepto de competencia. La centralidad de este concepto se basa en su capacidad de unir conceptualmente dos procesos fundamentales para el desarrollo económico de un país: la gestión de tareas y recursos humanos en la empresa y la formación para el empleo. Si se pudiera conocer de manera rigurosa y estructurada todo aquello que hace falta para realizar los distintos trabajos que se llevan a cabo en empresas e instituciones, es decir, las competencias, aquéllas podrían ser organizadas de manera más eficiente, entre otras cosas, porque con ese conocimiento se puede diseñar la formación de las personas trabajadoras de manera más eficiente y especializada.

Según el Servicio Público de Empleo Estatal, las competencias definen el ejercicio eficaz de las capacidades que permiten desarrollar una ocupación profesional con respecto a los niveles que requiere la tarea. Son algo más que el conocimiento técnico que hace referencia al saber y al saber hacer. El concepto de competencia no sólo engloba las capacidades requeridas para el ejercicio de una actividad profesional, sino también las requeridas para el conjunto de comportamientos, capacidad de análisis, toma de decisiones, transmisión de información, etc., que se consideran necesarias para el pleno desarrollo de la tarea.

A nivel general, no obstante, destaca la necesidad de favorecer una cualificación que permita la profesionalización de estas trabajadoras del servicio doméstico ${ }^{21}$, de forma que mejoren sus condiciones laborales o se favorezca su movilidad laboral a otra actividad profesional $^{22}$. Al respecto, la Recomendación 195 de la OIT es clara al mencionar: "Los Miembros deberían: [...] b) reconocer que la consecución del aprendizaje permanente debería basarse en un compromiso explícito: por parte de los gobiernos, de invertir y crear las condiciones necesarias para mejorar la educación y la formación en todos los niveles; por parte de las empresas, de formar a sus trabajadores; $y$, por parte de las personas, de desarrollar sus competencias $y$ trayectorias profesionales" 23 .

En este punto es importante destacar que, como venimos indicando, debido a la naturaleza del concepto, las competencias de las que dispone una persona no son inalterables, sino que pueden modificarse con la formación, la experiencia, etc. Por consiguiente, otro punto importante de la vigencia de las competencias es la posibilidad

Ministerio de Trabajo y Asuntos Sociales: Libro Blanco - Atención a las personas en situación de dependencia en España. IMSERSO, 2004, se estima que el volumen es importante. Tanto es así que esta tendencia es considerada un "fenómeno social emergente" (Instituto de la Mujer 2008 citado), que requiere de una mayor visibilización y un mayor conocimiento.

${ }^{20}$ Ley Orgánica 5/2002, de 19 de junio, de las Cualificaciones y la Formación Profesional.

${ }^{21}$ Ley Orgánica 5/2002, de 19 de junio, de las Cualificaciones y de la Formación Profesional.

22 Ver APARICIO RUIZ, M.G., La profesionalización de los empleados al servicio del hogar familiar (desde el contraste comparado de la normativa francesa), Ed. EOLAS EDICIONES, 2014, págs..209-228.

${ }^{23}$ Recomendación 195, párrafo 4, apartado b. 
de modificar el mundo de la educación y la formación profesional o profesionalizada para dar una respuesta directa a las necesidades reales a través de la formación en competencias . Pues aunque algunos de los servicios domésticos son rutinarios, quien los realice debe poseer los conocimientos adecuados que le permitan optimizar el tiempo, el espacio, los recursos materiales y los humanos.

Por estas razones, les corresponde a los distintos agentes sociales, conseguir que el desarrollo profesional sea una estrategia empresarial clave, si quieren sobrevivir en el entorno empresarial cada vez más competitivo. Pero el horizonte de la formación profesional por parte del empleador en el sector objeto de estudio es muy limitado; por lo que las interesadas deberán acudir a cursos que se oferten fuera del seno del hogar familiar que les permitan profesionalizarse y mejorar sus oportunidades de empleo, ya que el "aislamiento" que va ligado al trabajo en el ámbito doméstico favorece bastante entre otros factores negativos la dificultad a la hora de poner en práctica la formación profesional con el perfil objeto de examen.

\section{LA FORMACIÓN PROFESIONAL COMO ELEMENTO CLAVE EN EL NUEVO ESTATUTO JURÍDICO}

Como sabemos, las actividades dedicadas al cuidado de hogar y personales eran actividades tradicionalmente desarrolladas por las mujeres del entorno familiar; una actividad que era aprendida de generación en generación, de esta forma se adquirían los conocimientos necesarios para desempeñar estas tareas. El 90\% de las personas ocupadas en el sector son mujeres, porcentaje que apenas se reduce, si se considera de manera aislada el sector formal (81\%). El índice de segregación ocupacional llega a alcanzar, de este modo, una cifra récord, con 937 mujeres ocupadas en el sector por cada 100 hombres, lo mismo que el índice de representación ${ }^{24}$.

Ésta práctica, fomentó por error, una idea socialmente extendida, de que cualquier mujer por el hecho de serlo, sin necesidad de un aprendizaje o formación específica, estaba capacitada y podía realizar este trabajo ${ }^{25}$. Estas tareas carecían de una reglamentación laboral que estableciera las condiciones de trabajo y que regulara derechos y deberes que habrían de presidir las relaciones entre empleadores y

\footnotetext{
${ }^{24}$ CACHON RODRIGUEZ, L., “La formación y los “nuevos yacimientos de empleo” en España”. Reis: Revista española de investigaciones sociológicas, núm. 77-78, págs. 117-136.

25 SARASÚA GARCÍA, C., Criados, nodrizas y amos: El servicio doméstico en la formación del mercado de trabajo madrileño, 1758-1868. Editorial: Siglo XXI de España Editores, S.A., 1994, págs. 23 y ss. Tenemos que considerar el paternalismo como la relación más común dentro del servicio doméstico desde finales del siglo XIX hasta la década de los sesenta. Durante este periodo eran los padres quienes confiaban a la hija al servicio de una casa y transmitían su responsabilidad paterna a los señores de la misma. Los señores, a partir de entonces, debían ocuparse de la educación y alimentación de esa muchacha, asimismo debían mantener el contacto con los padres de esta para comentarles su evolución. Se trataba de una relación ilimitada porque estas chicas entraban en el servicio doméstico como un destino vitalicio. De hecho, la vida de la criada guardaba muchísimas similitudes con la vida monacal.
} 
empleados: salario mínimo, forma de trabajo, despidos, seguridad social, etc. Como consecuencia de ello accedían a estos trabajos personas sin una formación específica y sin ninguna vocación profesional, lo que hacía que se devaluara socialmente la dignidad del personal que desempeñaba estos servicios ${ }^{26}$. Este tópico, por lo menos durante los años sesenta, se acercaba bastante a la realidad, y siendo muchísimas las mujeres que emigraron del campo a la ciudad por iniciativa propia ${ }^{27}$.

\section{LA PROFESIONALIDAD COMO ELEMENTO SUSTANTIVO EN LA PRESTACIÓN DEL TRABAJO DOMÉSTICO}

En la actualidad, con los cambios sociales acaecidos y la externalización de las tareas, las exigencias en cuanto a capacitación de las personas trabajadoras, que trataremos en el epígrafe siguiente, son mayores, y es ahora cuando se empieza a valorar la necesidad de una formación previa, primordialmente en tareas que están relacionadas con los cuidados personales ${ }^{28}$. La práctica que se adquiere mediante la formación profesional, modifica, moldea y enriquece la profesionalidad del trabajador, elemento de reveladora importancia en la relación de trabajo, puesto que resulta inseparable al carácter personalísimo de ésta relación. A diferencia de la situación "tradicional”, ahora se quiere cada vez más, "un profesional”29. En realidad, lo que esto parece indicar, es que la tendencia actual va en la dirección de seleccionar personas más productivas ${ }^{30}$.

Pero en este sentido, cuando procedemos a analizar en profundidad, la legislación existente en relación con la profesionalidad de estas trabajadoras, observamos que ante las carencias y lagunas existentes, la doctrina judicial ha optado por excluir del concepto

\footnotetext{
${ }^{26}$ VÁZQUEZ, J.M., El servicio doméstico en España. Su situación real y propuesta de resolución para sus problemas, Madrid, Ed. Instituto Nacional de Previsión, Serie Estudios Premio Marvá, 1960, pág. 18: "En general las chicas de servicio de las grandes ciudades poseen más cualidades negativas que positivas. Salidas de un ambiente tosco y sin conocimiento alguno de los hombres y de la vida, son fácil presa de las insidias de la ciudad. Asimilan lo malo de ésta y no se desprenden de la tosquedad rural de donde proceden. Al mismo tiempo que ayudan, comienzan por ser un problema para el ama de casa. Pero ¿es que la chica que tuviera más preparación cultural, religiosa y profesional aceptaría el servicio en las condiciones en que se realiza actualmente en España? Indudablemente, no". En el texto el autor criticaba las condiciones en las que se desarrollaba el servicio doméstico en España, pero deja claro que las chicas de servicio poseían escasas aptitudes y por ello no se podían emplear en otro oficio.

27 "El trabajo a domicilio constituyó en gran medida la única alternativa laboral que se ofrecía a muchas mujeres españolas en este periodo. Al tratarse de una mano de obra poco cualificada, las mujeres se orientaban profesionalmente hacia aquellos sectores que requerían pocos conocimientos técnicos.". MARY NASH. A., "20 años de Historia de las Mujeres". Arenal: Revista de historia de mujeres, Vol. 20, $\mathrm{n}^{\circ} 1$, 2013, págs. 4-5.

${ }^{28}$ Notas sobre Auxiliares Domésticas o servicio de Trabajadoras familiares. OIT: Boletín Oficial (Ginebra), julio de 1965, Suplemento I, págs. 19 y 20.

${ }^{29}$ La normativa que regula actualmente los certificados de profesionalidad es el R.D. 34/2008, de 18 de enero.

${ }^{30}$ El certificado de profesionalidad es el instrumento de acreditación oficial de las cualificaciones profesionales del Catálogo Nacional de Cualificaciones Profesionales en el ámbito de la Administración laboral, que acredita la capacitación para el desarrollo de una actividad laboral con significación para el empleo y asegura la formación necesaria para su adquisición, en el marco del subsistema de formación profesional para el empleo regulado en el Real Decreto 395/2007, de 23 de marzo.
} 
de trabajadores al servicio del hogar familiar a profesionales cualificados, por su “tipicidad y especialización”, salvo que no lleven a cabo tareas especializadas o no sólo especializadas $^{31}$.

Por ello no podemos olvidar la importancia que hoy día tienen los sistemas de cualificaciones profesionales, que debe principalmente potencializar ampliar mejoras relativas a la cualificación y formación profesional de la población activa ${ }^{32}$, es decir impulsar nuevas formas de aprendizaje ${ }^{33}$, articular todas las diversas formas del mismo con su regulación, reconocimiento oficial y valoración, estimular el aprendizaje permanente, mejorar el vínculo entre el mundo de la educación-formación y el mundo del trabajo, y proporcionar transparencia al intercambio de oferta y demanda de cualificaciones en el mercado laboral.

Pero en un contexto social como el actual, todo lo anterior podría considerarse una meta de difícil realización, ya que a pesar de lo recurrente de la igualdad de oportunidades, no es en este sector lo habitual la formación adicional de conocimientos por parte del empleador; ya que desde la escasa valoración social que se concede a este trabajo y a las personas que lo realizan, no entra dentro de sus expectativas. Todo ello, entendemos que se da por la ambigüedad que rodea a este tipo de trabajo, como forma de empleo o profesión, por lo que de lege refenda debería considerarse valorar la cualificación y el mérito de las tareas concretas para las que son contratadas.

\subsection{La capacitación como factor modulador de la profesionalidad del trabajador}

Nos encontramos, como a lo largo de la historia, las personas han venido realizando tareas propias de la profesión, pero, su actuación se basaba más en la intuición que en el conocimiento, esto significa, que es del todo necesario que, para que a una tarea se le pueda calificar de "profesional”, la práctica necesariamente debe ir acompañada también de la teoría ${ }^{34}$, ya que por separado, pierden el calificativo de "profesional", del que no existe definición de este "concepto difícil" 35 . Y es que la

\footnotetext{
${ }^{31}$ Así no los considera empleados de hogar si realizan tareas sanitarias especializadas (STCT de 25 de noviembre de 1977, As.5917, 5 de febrero de 1985, Ar.766, 1 de julio de 1987, Ar.5052), salvo que además de las funciones de ATS realicen funciones no circunscritas a las técnicas, propias de su profesión, sino cuantas abarca el cuidado de las personas de las que se hace cargo numerosas sentencias del TCT y STSJ Cantabria de 27 de julio de 1991, As.4489, Baleares de 16 de junio de 1994, Ar.2618).Véase CUEVA PUENTE, C., La relación laboral especial de los empleados de hogar. Lex Nova, 2005. págs. 174-175.

32 Sirva como ejemplo:

http://www2.sepe.es/sggfo/FormacionOcupacional/Documentos/ProgCursosNuevas/SSCD10_p.pdf (consultado el 11/02/2019).

33 D'IRIBARNE, A. (1996): “Una lectura para los paradigmas del Libro blanco sobre la educación y la formación”, Revista europea de formación profesional, 8-9, págs. 24-32.

${ }^{34}$ Al respecto, Recomendación OIT 195, párrafo 4, apartado b. “Los Miembros deberían: [...] b) reconocer que la consecución del aprendizaje permanente debería basarse en un compromiso explícito: por parte de los gobiernos, de invertir y crear las condiciones necesarias para mejorar la educación y la formación en todos los niveles; por parte de las empresas, de formar a sus trabajadores; $y$, por parte de las personas, de desarrollar sus competencias y trayectorias profesionales”.

35 CASTIÑEIRA FERNANDEZ, J., "La tutela de la profesionalidad del trabajador, la formación y readaptación profesionales y el estatuto de los trabajadores”. RPS, 121, 1979, pág. 126.
} 
preocupación por cómo se aprende viene de antiguo. A este respecto, Gómez Llorente señala que "El aprendizaje a lo largo de toda la vida es tan antiguo como la propia humanidad. Lo moderno es la reflexión crítica y el debate en torno a él” 36 .

En un primer momento, se consideró la profesionalidad como "el conjunto de conocimientos y capacidad, derivada de la formación de base (título de estudio o nivel cultural equivalente), del conocimiento profesional especifico, de la experiencia adquirida y concretamente utilizable ${ }^{\text {37 }}$. Esta definición responde a lo que se suele denominar como patrimonio profesional del trabajador, identificable con el nivel profesional, la aptitud o capacidad individual de aquél ${ }^{38}$.

El reconocimiento y la conservación de éste patrimonio es lo que se constituye como tutela estática de la profesionalidad. Ahora bien, la protección legal de la misma abarca también "una perspectiva dinámica del progreso en la capacidad profesional”39. Esta es una clara referencia a la tutela dinámica de la profesionalidad, caracterizada por la búsqueda de un desarrollo de la capacidad profesional ${ }^{40}$. La consecuencia es el reenvío de la nota de progreso hacia la noción de la profesionalidad, conceptuada ahora como "adquisición continua de nuevas aptitudes que colocan al

\footnotetext{
${ }^{36}$ GOMEZ LLORENTE, L. "El Aprendizaje a lo Largo de Toda la Vida. En Aprender a lo largo de la vida”. Participación Educativa ${ }^{\circ}$ 9. noviembre 2008. págs. 7-13.

http://www.academia.edu/175351/Nativos_e_inmigrantes_digitales_en_la_escuela (consultado el 09/02/2019)

37 CASTIÑEIRA FERNANDEZ, J. La tutela de la profesionalidad del trabajador, la formación y readaptación profesionales..., op. cit., pág. 126.

38 VALDÉS DE LA VEGA, B., La profesionalidad del trabajador en el contrato laboral. Ed. Trotta. 1997, pág. 18.

${ }^{39}$ BAYLOS GRAU, A. "La carrera profesional del trabajador: promoción y ascensos en el Derecho del Trabajo”. Revista Documentación Administrativa, 210/211. 1987. pág. 207.

http://revistasonline.inap.es/index.php?journal=DA\&page=article\&op=view\&path\%5B\%5D=4946\&path \%5B\%5D=5000 (Consultado el 30/01/2019).

${ }^{40}$ La norma UNE 66173 (UNE 66173. Los recursos humanos en un sistema de gestión de la calidad: gestión de las competencias (2003). Madrid: AENOR. pág. 4.), entiende por competencia el conjunto de "atributos personales y (la) aptitud demostrada para aplicar conocimientos y habilidades". Se señala de modo expreso que es sinónimo de la "capacidad de resolver problemas en un determinado contexto". El análisis de esta normativa nos permite señalar las siguientes dimensiones que integran el concepto de competencia, por un lado los atributos personales o cualquier talante que pertenezca al ámbito del sujeto, esto es, aquellos rasgos que posee una persona bien de nacimiento o adquiridos por formación y que definen lo que la persona es (frente a lo que hace) tales como: talento, motivación, comunicación, capacidades cognitivas, valores, inteligencia emocional u otros como conocimientos (saber) y habilidades (saber hacer), que aún no siendo típicamente rasgos son incluidos por la mayoría de los autores bajo esta categoría, por otro las aptitudes demostradas (hacer) conforman las conductas observables como respuesta a los estímulos en un entorno real. Se trata de primar aquello que hace una persona (frente a lo que es). Se trata de destrezas y habilidades aplicadas, y por último la capacidad demostrada para resolver problemas en cualquier contexto; esa capacidad para asumir presciencias e incertidumbres derivadas de cualquier entorno en el tiempo (competencias requeridas, disponibles y potenciales). Aspecto que a nuestro entender parece difícil de adquirir, gestionar y de aplicar.
} 
trabajador en disposición de mejorar su propia capacidad de trabajar y desempeñar funciones siempre nuevas y diversas" 41 .

En palabras de Valdés de la Vega, debemos deslindar lo que puede entenderse como concepto de profesionalidad, de aquello otro que constituye su tutela. Desde este punto de vista, la profesionalidad hace referencia a lo que es propio de la persona del trabajador, y que sirve para la realización de la actividad laboral ${ }^{42}$. Comprende, por tanto, todo aquello que el trabajador posea como suyo y precise para efectuar el trabajo, por lo que, dependiendo de cuál sea este, el contenido técnico concreto de la profesionalidad de cada trabajador variara. Sera diferente en función de la rama de actividad y especialidad de que se trate. Se debe resaltar, no obstante, que este contenido variable no debe impedir la delimitación de unas notas definitorias del concepto de profesionalidad ${ }^{43}$.

En el ámbito objeto de estudio, existen muchas personas, que a pesar de haber estado trabajando durante mucho tiempo en un hogar familiar, no disponen de dicha acreditación ${ }^{44}$, que estaría integrada por el "conjunto de actuaciones dirigidas a evaluar y reconocer las competencias profesionales ${ }^{45}$ adquiridas a través de la experiencia laboral o de aprendizajes considerados no formales". Dispositivo al que, "quienes voluntariamente lo deseen, pueden acudir para demostrar las competencias profesionales que posean, cualquiera que sea la forma de su adquisición”, todo ello con alcance y validez para todo el territorio nacional.

\footnotetext{
${ }^{41}$ PEREZ-ESPINOSA SÁNCHEZ, F. “Organización del trabajo, sistema de clasificación en categorías y defensa de la profesionalidad del trabajador”. Lecciones de Derecho del Trabajo, Universidad Complutense, Madrid, 1980, pág. 183.

${ }^{42}$ El concepto de "desarrollo de las competencias profesionales" se entenderá en un sentido amplio, conforme con los términos de las Conclusiones sobre la formación y el desarrollo de los recursos humanos (OIT, 2000a, párrafo 5), que abarca la enseñanza básica, la formación inicial y el aprendizaje a lo largo de toda la vida.

${ }^{43}$ VALDÉS DE LA VEGA, B. La profesionalidad del trabajador... op. cit., pág. 18.

${ }^{44}$ Regulado en el Real Decreto 1224/2009, de 17 de julio, de reconocimiento de las competencias profesionales adquiridas por experiencia laboral, que tiene como objeto establecer el procedimiento y los requisitos para la evaluación y acreditación de las competencias profesionales adquiridas por las personas a través de la experiencia laboral o de vías no formales de formación, así como los efectos de esa evaluación de competencias. Los ciudadanos/as que decidan obtener un reconocimiento oficial de su experiencia deberán inscribirse en la convocatoria anual que realice la administración competente. Los requisitos que han de cumplir para participar en el reconocimiento son poseer la nacionalidad española, tener 18 años cumplidos en el momento de realizar la inscripción, tener experiencia laboral y/o formación relacionada con las competencias profesionales que se quieren acreditar: en el caso de experiencia laboral: justificar, al menos, 3 años, con un mínimo de 2.000 horas trabajadas en total, en los últimos 10 años transcurridos antes de realizarse la convocatoria, en el caso de formación: justificar, al menos 300 horas, en los últimos 10 años transcurridos antes de realizarse la convocatoria.

${ }^{45}$ CRUZ, P. K., y VEGA, G. M.: La gestión por competencias: una nueva herramienta en la planificación estratégica del recurso humano, Antofagasta, Ed. Universidad de Antofagasta, 2001, pág. 10, "modelo de gestión que permite evaluar las competencias específicas que requiere un puesto de trabajo de la persona que lo ejecuta, además, es una herramienta que permite flexibilizar la organización, ya que logra separar la organización del trabajo de la gestión de personas, introduciendo a estas como actores principales en los procesos de cambio de las empresas y finalmente, contribuir a crear ventajas competitivas de la organización"
} 
Como observamos, la “cualificación profesional” se acredita mediante un certificado según el Real Decreto 797/1995, de 19 de mayo, por el que se establece directrices sobre los certificados de profesionalidad y los correspondientes contenidos mínimos de formación profesional ocupacional, "el certificado de profesionalidad tiene por finalidad acreditar las competencias ${ }^{46}$ profesionales adquiridas mediante acciones de formación profesional ocupacional, programas de escuelas taller y casas de oficios, contratos de aprendizaje, acciones de formación continua, o experiencia profesional". Ello quiere decir por tanto, que la profesionalidad se puede adquirir por vía formativa, por experiencia, o por una combinación de ambas ${ }^{47}$.

Esta necesidad de aprender, en cuanto se relaciona con el mundo del trabajo, adquiere un significado vinculado con el grado en que la disposición de competencias requeridas en dicho campo laboral es crucial para el empleo. Disponer de competencias acordes con la demanda de los puestos de trabajo continúa siendo clave en el éxito laboral, pero ahora tal requerimiento se ha tornado más dinámico, los empleos cambian, la forma en que se accede a ellos también, las tecnologías en uso lo hacen y las formas en que se organiza el trabajo, en que interactúan las personas, en que se dan y reciben instrucciones, se crean compromisos y se obtienen resultados, también varían y no olvidemos que esto sucede muy rápido.

Entonces, una clave en la posibilidad de mantener un acervo de competencias valiosas para el empleo es que exista una oferta permanente de conocimientos y cualificaciones. Otra clave es que la oferta esté complementada con la actitud del individuo por

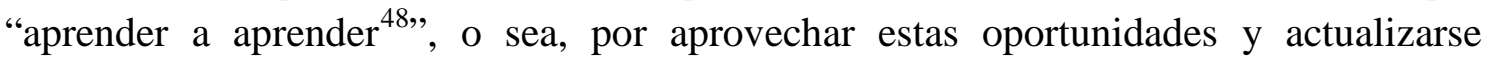

\footnotetext{
${ }^{46}$ La OCDE se ocupó de analizar los sistemas de formación y su incidencia en la promoción del aprendizaje a lo largo de la vida. En su publicación titulada Moviendo montañas: cómo los sistemas de cualificación pueden promover el aprendizaje a lo largo de la vida (Moving Mountains: How can qualifications systems promote lifelong learning, OCDE, 2005), se reconoce la importancia de este enfoque por su relación con el bienestar de la sociedad y la productividad de la economía de los países.

El aprendizaje a lo largo de la vida es concebido como "todas las actividades educativas emprendidas a través de la vida, con el objetivo de incrementar el conocimiento, las habilidades, las competencias o las cualificaciones, por razones personales, sociales o profesionales".

El análisis de la OCDE incorpora conceptos acerca del trabajo y la formación cuyo uso relativamente nuevo requiere de un entendimiento común para facilitar la comprensión y la unidad de criterios. Tal es el caso de los términos “competencia” y “cualificación”.

Competencia se entiende como una capacidad que va más allá de la posesión del conocimiento y las habilidades y está conformado por: a) competencia cognitiva, que comprende el uso de teorías y conceptos, como también el conocimiento tácito informal obtenido con la experiencia; b) competencia funcional (habilidades o saber hacer), que cubre las cosas que las personas están en capacidad de hacer cuando trabajan en un área determinada; c) competencia personal, que cubre el saber comportarse en una situación específica, y d) la competencia ética, que abarca la posesión de ciertos valores personales y profesionales.

Por su parte, el término cualificación es definido en el mismo texto de la OCDE como el resultado formal de un proceso de acreditación o validación. La cualificación confiere un reconocimiento oficial de valor en el mercado del trabajo y en la educación o formación posterior.

${ }^{47}$ Sirva de ejemplo el auxiliar de ayuda a domicilio. (RD 331/1997 de 7/3/97, BOE 73, 26/3/97).

${ }^{48}$ Una de las ocho competencias básicas que la Comisión Europea (2004) propuso es la de Aprender a aprender que, en cierto sentido, subyace a todas las demás. Definir esta competencia resulta complejo, debido a la cantidad de matices en los que se puede poner la atención y al carácter transversal de la
} 
permanentemente. En este contexto, aprender a aprender ${ }^{49}$ se convierte en la herramienta por antonomasia que garantiza la educación y la capacitación a lo largo de la vida para toda la ciudadanía, incluyendo a las personas con pocas oportunidades como sucede en este sector, en cualquiera de los escenarios posibles de aprendizaje (formal, no-formal o informal).

En los tiempos de crisis en los que nos encontramos, se habla mucho de la formación que ha de aportar todo trabajador para optar a un puesto de trabajo ${ }^{50}$, pero a la hora de elegir una persona empleada de hogar, entendemos que lo primero que deberíamos tener en cuenta son las necesidades que tenemos, ya que deben existir perfiles profesionales de servicio doméstico distintos, según estén dedicados a unas actividades u otras (cuidado de niños, cuidado de personas mayores, o exclusivamente la realización de las tareas del hogar), como analizaremos posteriormente.

\subsection{La adquisición del Certificado de profesionalidad y los estándares de calidad en la presentación del servicio doméstico}

Debido a la regulación de los certificados de profesionalidad de la familia profesional servicios socioculturales y a la comunidad, que son, en el marco de la Formación para el Empleo, las enseñanzas dirigidas a la obtención y certificación de las competencias contenidas en una cualificación profesional, aprobados por el Real decreto 139/2008, de 1 de agosto, de atención socio-sanitaria a personas en el domicilio y atención socio-

misma. En este sentido, en la primera década del siglo XXI han cristalizado diversas iniciativas internacionales, cuyo interés se ha centrado en las competencias básicas: la Organización para la Cooperación y el Desarrollo Económico (OECD-OCDE) y la Oficina Estadística Federal de Suiza impulsaron el mencionado proyecto DeSeCo (definición y selección de competencias, 2003); Eurydice reunió (2002) información acerca de las competencias; la Comisión Europea presentó una propuesta (2004) para el reconocimiento de las competencias clave; la UNESCO realizó un informe sobre las habilidades para la vida en una educación para todos (2002); el estudio PISA también dio a conocer un informe sobre resolución de problemas para el mundo del mañana (2004); la universidad de Helsinki, partícipe del proyecto LEARN ("Life as Learning”) ha organizado varios estudios sobre aprender a aprender.

Comisión Europea (2004): Competencias clave para el aprendizaje permanente. Un Marco de Referencia Europeo. Bruselas.

http://ec.europa.eu/dgs/education_culture/publ/pdf/lllearning/keycomp_es.pdf (consultado el 24/01/2019) "La habilidad para iniciar el aprendizaje y persistir en él, para organizar su propio aprendizaje y gestionar el tiempo y la información eficazmente, ya sea individualmente o en grupos. Esta competencia conlleva ser consciente del propio proceso de aprendizaje y de las necesidades de aprendizaje de cada estudiante, determinar las oportunidades disponibles y ser capaz de superar los obstáculos con el fin de culminar el aprendizaje con éxito. Dicha competencia significa adquirir, procesar y asimilar nuevos conocimientos y capacidades, así como buscar orientaciones y hacer uso de ellas. El hecho de "aprender a aprender" hace que los alumnos y alumnas se apoyen en experiencias vitales y de aprendizaje anteriores con el fin de utilizar y aplicar los nuevos conocimientos y capacidades en muy diversos contextos, como los de la vida privada y profesional y la educación y formación. La motivación y la confianza son cruciales para la adquisición de esta competencia”

${ }^{49}$ MARTÍN ORTEGA, E. (2008): “Aprender a aprender: clave para el aprendizaje a lo largo de la vida”. En Participación Educativa, núm. 9 (revista del Consejo Escolar del Estado), noviembre 2008, págs. 7278.

${ }^{50}$ DELCOURT, J.: Nuevas presiones a favor de la formación en la empresa, Formación Profesional, (17), 1999. págs. 3-14. El artículo puede consultarse en http: //www.trainingvillage.gr, elaborada por CEDEFOP (Centro Europeo para el Desarrollo de la Formación Profesional). 
sanitaria a personas dependientes en instituciones sociales ${ }^{51}$ (dicha ley define al cuidador profesional como el trabajador que proporciona cuidados en una institución pública o entidad, con y sin ánimo de lucro, o el profesional autónomo que presta servicios a personas en situación de dependencia, ya sea en su hogar o en un centro ${ }^{52}$, consideramos necesaria una nueva reflexión, sobre cómo ha influido lo regulado en el actual mercado laboral nacional, sobre todo tras la normativización del sector de la dependencia $^{53}$, a la que me referiré en el siguiente epígrafe.

La regulación de la Ley 39/2006 de 14 de diciembre, de promoción de la autonomía personal y atención a las personas en situación de dependencia, está permitiendo mejorar la calidad de los servicios de atención y, al mismo tiempo, garantiza la calidad del empleo de los profesionales que desarrollan su actividad en este sector ${ }^{54}$. En este sentido, en el artículo 36.1 de la propia Ley 39/2006, de 14 de diciembre, se establece la obligación del sector público de proporcionar la "formación básica y permanente de los profesionales y cuidadores que asistan a las personas dependientes" ${ }^{55}$, dictaminando para ello que los poderes públicos determinarán las cualificaciones profesionales idóneas ${ }^{56}$ para el ejercicio de las funciones relacionadas con el catálogo de servicios incluido en la Ley, promoviendo las acciones formativas necesarias para garantizar la implantación y calidad de los mismos ${ }^{57}$.

${ }^{51}$ ESPARZA CATALÁN, C. Discapacidad y dependencia en España. Madrid, Informes Portal Mayores,
$\mathrm{n}^{\mathrm{o}} \quad$ 108. 2011. (Fecha de publicación: 08/04/2011). Disponible en: http://www.imsersomayores.csic.es/documentos/pm-discapacidad-01.pdf (consultado el 11/02/2019)

${ }^{52}$ La aplicación de la Ley de dependencia en España. GONZÁLEZ ORTEGA, S., director de la investigación; Margarita Arenas Viruez y otros, $1^{a}$ ed. Madrid. Consejo Económico y Social (España). 2013, págs. 57 y ss.

53 Cada certificado, a pesar de tener como objetivo común la atención a personas en situación de dependencia, tiene objetivos y características diferentes. El certificado de profesionalidad de atención socio-sanitaria a personas en el domicilio (600 horas), tiene como objetivo principal "ayudar en el Ámbito socio-sanitario en el domicilio a personas con especiales necesidades de salud física, psíquica y social, aplicando las estrategias y procedimientos más adecuados para mantener y mejorar su autonomía personal y sus relaciones con el entorno". Sin embargo, el certificado de profesionalidad de atención socio-sanitaria a personas dependientes en instituciones sociales (450 horas), tiene como objetivo “atender a personas dependientes en el ámbito socio-sanitarios en la institución donde se desarrolle su actuación, aplicando las estrategias diseñadas por el equipo interdisciplinar competente y los procedimientos para mantener y mejorar su autonomía personal y sus relaciones con el entorno".

54 DINAMIA. Conclusiones y Recomendaciones, Estudio sobre necesidades de cualificación de las personas trabajadoras con funciones de atención directa a la situación de dependencia, Informe diciembre- 2008,

http://www3.feccoo.net/bdigital/priv/20081217_priv/pdf/confe_estnecformdpend.pdf （consultado el 30/01/2019).

55 ROQUETA BUJ, R., La protección de la dependencia, comentarios a la ley 39/2006, de 14 de diciembre, de promoción de la autonomía personal y atención a las personas en situación de dependencia, Ed. Tirant lo Blanch, Valencia, 2007, pág. 23.

${ }^{56}$ MONTOYA MELGAR, A. La protección de las personas dependientes. Ed. Civitas. 2007. págs. 78 y ss.

57 TEJADA-FERNÁNDEZ, J. Perfiles profesionales en la atención a personas dependientes: una mirada desde la formación. Ed. Universitat Autònoma de Barcelona. 2009, págs. 11-13.

file:///C:/Users/CeXX/Downloads/Dialnet-PerfilesProfesionalesEnLaAtencionAPersonasDependie-

3011802.pdf (consultado el 20/02/2019) 
En este sentido, se debe destacar que diferentes informes realizados por el Comité de Representantes de personas con discapacidad, el Observatorio Nacional de la Dependencia y el IMSERSO ${ }^{58}$, en lo referente a los profesionales del sector, ponen de manifiesto su escasez, proponiendo que se conceda carácter prioritario a la formación de los profesionales vinculados a los servicios de atención a la dependencia ${ }^{59}$.

Es cierto que la atención a personas dependientes, se ha erigido en uno de los yacimientos de empleo más relevante en los últimos años ${ }^{60}$, con una gran necesidad de trabajo, hasta el punto que alguna de las ofertas no se cubrían; La realidad de estos datos evidencia una falta de profesionales agravada a su vez, como decimos, por la falta de reconocimiento de otros tantos que se encuentran satisfaciendo necesidades de este ámbito laboral. A ello debemos añadir la difusa conceptualización de los servicios, la ausencia de definición de los perfiles profesionales, la carencia de títulos, todo ello, en correspondencia con las exigencias en el sector, ya que en estos casos mucho aprendizaje adquirido se realiza a través de la experiencia.

\subsection{El objetivo del reconocimiento de las cualificaciones profesionales como factor determinante en la mejora de prestación del servicio}

La importancia que hoy día tienen los sistemas de cualificaciones profesionales se debe principalmente a su gran potencialidad para articular y efectuar un amplio grupo de mejoras relativas a la cualificación y formación profesional de la población activa, esto es, impulsando nuevas formas de aprendizaje, articulando todas las diversas formas del mismo con su regulación, reconocimiento oficial y valoración (por parte de las personas, la economía y la sociedad), estimulando el aprendizaje permanente, mejorando el vínculo entre el mundo de la educación/formación y el mundo del trabajo, y proporcionando transparencia al intercambio de oferta y demanda de cualificaciones en el mercado laboral.

La necesidad de lograr la citada transparencia, que no significa otra cosa que conseguir una definición precisa del contenido de las cualificaciones que se ofertan y

\footnotetext{
${ }^{58}$ Análisis de los desarrollos normativos del Sistema para la Autonomía y Atención a la Dependencia (SAAD). Estudio comparativo autonómico. (2009). Comité de Representantes de Personas con Discapacidad. (CERMI). Informe Implementación Ley Dependencia en España: valoración CCAA. Borrador informe: Alicia Azaña. Universidad de Valencia, 22 enero 2009. Informe Final del Grupo de Expertos para la Evolución del desarrollo y efectiva aplicación de la Ley 39/2006 14 de diciembre de promoción de la Autonomía Personal y Atención a las Personas en Situación de Dependencia. IMSERSO, septiembre 2009.

59 BERMEJO GARCIA, L., "La situación de los sistemas de formación y de cualificación de las ocupaciones en la atención a mayores dependientes. Propuestas de avance en la elaboración de perfiles ocupacionales y en la formación por competencias”. Madrid, portal mayores, informes portal mayores n50. 2006, págs. 11-16.

http://www.imsersomayores.csic.es/documentos/documentos/bermejo-situacion-01.pdf (Consultado el 30/01/2019)

60 ARAGÓN MEDINA, J., CRUCES AGUILERA, J., y ROCHA SÁNCHEZ, F. Las condiciones laborales en el sector de atención a la dependencia: una aproximación de calidad en el empleo. 2008. Fundación $1^{\circ}$ de Mayo. Documento de Trabajo 2/2008, pág. 5.
} 
demandan en el mercado laboral, se comprende inmediatamente si se consideran los desajustes, existentes en ocasiones, entre las expectativas de empleadores y trabajadores, que acarrean la falta de información sobre las competencias o destrezas que se demandan u ofertan en el mercado de trabajo del servicio doméstico. En cambio, si la oferta y demanda de trabajo se realizan en términos explícitos (transparentes), esto es, en términos de las competencias especificadas en las cualificaciones de un sistema nacional, resulta claro que se reducen sensiblemente los citados desajustes, lográndose una relación laboral más rápida y eficaz.

Contribuiría a ésta transparencia, el establecimiento de un conjunto (o catálogo) de cualificaciones profesionales que constituyan el marco necesario para hacer más transparente el mercado laboral de éste sector, que tal y como está regulado, no logra dicha transparencia. Para ello es preciso que los sujetos reales que forman parte del sector acrediten la certificación de sus respectivas competencias o cualificaciones y como consecuencia encontraríamos una mejora de las relaciones entre la oferta y demanda de trabajo.

\subsection{La ausencia de reconocimiento de cualificación y acreditación profesional en consonancia con su trabajo en el sector analizado.}

Asimismo, la falta de reconocimiento incide desfavorablemente sobre los aprendizajes de muchas mujeres, los cuales quedan ensombrecidos al ser realizados, en muchos casos, en el ámbito doméstico, un ámbito al que no se reconoce valor de mercado $\mathrm{y}$, por tanto, resulta difícil hacerlos visibles en un contexto que no los reconoce.

Por esta razón, entendemos que la capacitación en este sector es una necesidad que hoy en día nadie duda, cualificaciones que favorecerían el reconocimiento social de la labor y de sus trabajadoras, pero la realidad es que existen grandes carencias en adecuar los conocimientos, actitudes y motivación requeridos para realizar este trabajo, y las competencias profesionales y personales de las personas trabajadoras que las van a desarrollar $^{61}$. Nos inclinamos a pensar que se debe concienciar a las trabajadoras sobre la importancia de la formación y a su vez, realizar una mayor difusión de la posible oferta formativa.

Por ello, es necesario hacer visibles esos aprendizajes, incidiendo directamente en su reconocimiento y validación. La valoración del trabajo doméstico y de cuidados, que se está haciendo desde distintas aproximaciones, es un buen indicador para su estimación porque al hacerlo explícito incide directamente en la necesidad de su reconocimiento y validación.

\footnotetext{
${ }^{61}$ LABRUFFE, A., La gestión de competencias: planteamientos básicos, prácticas y cuadros de mando. Madrid: Ed. AENOR. 2008, pág. 186.
} 
Así, el Instituto Nacional de Estadística (en adelante INE) ${ }^{62}$ ha estudiado el valor del trabajo realizado en la familia, principalmente por mujeres, y que no se computa en el producto interior bruto. En ese estudio se identifican las actividades relacionadas con el hogar y la familia que no tienen valor de mercado, se cuantifica el tiempo dedicado a ellas y les asignan una remuneración simulada para calcular su valor. Como resultado, concluyen que las mujeres aportan el 73\% del trabajo para la realización de las actividades no de mercado y, por tanto, no remuneradas. Tal producción supone más del 27\% del PIB nacional, unos 285.600 millones de euros. De ese modo, estas "cuentas satélites” ${ }^{23}$ permiten un mejor conocimiento de la distribución del trabajo remunerado y no remunerado entre mujeres y hombres y con ello, contribuyen a su valoración, visibilizando los elementos subyacentes que dificultan la conciliación entre la vida familiar y la laboral ${ }^{64}$. Y son una buena base de lo que es preciso hacer en relación con la valoración y certificación de las competencias adquiridas (no formales e informales) en el trabajo fuera del mercado laboral.

En cualquier caso, conviene recordar aquí que su impulso y desarrollo tiene gran importancia, y por ello está recogido en un estudio de la Fundación Tripartita para la Formación en el Empleo (Boletín electrónico, diciembre 2007) ${ }^{65}$. En el mismo se concluye que en España existe un volumen importante de aprendizaje no formal cuya falta de reconocimiento incide más directamente sobre determinados grupos de población ${ }^{66}$, en los que puede provocar situaciones de deficiente transición al mercado laboral con el consiguiente riesgo de exclusión.

Asimismo, la falta de reconocimiento incide desfavorablemente sobre los aprendizajes de muchas mujeres del sector, los cuales quedan ocultos al ser realizados, en muchos casos, en el ámbito doméstico, un ámbito al que, como ya hemos mencionado, no se reconoce valor de mercado y, por tanto, resulta difícil hacerlos

62

https://www.ine.es/prodyser/espa_cifras/2018/files/assets/common/downloads/publication.pdf?uni=4f7e7 b429c56ccbc4bf56b3e93ebc47b

http://www.sepe.es/contenidos/que_es_el_sepe/publicaciones/pdf/pdf_mercado_trabajo/imt2016_datos20 15_estatal_mujeres.pdf (consultado el 30/01/2019).

${ }^{63}$ Las cuentas satélites son un sistema de organización de las contabilidades nacionales para medir el valor de los sectores económicos que no se reflejan como tales en las cuentas nacionales. Por ello, la cuenta satélite del trabajo no remunerado funciona de forma paralela a las cuentas nacionales, sin alterar los totales nacionales, en este caso regionales, ofreciendo cifras que cuantifican la contribución real del trabajo no remunerado al Producto Interior Bruto (PIB) y permitiendo la comparación con otros sectores económicos contemplados en la contabilidad regional o nacional. BENERÍA, L., "El debate inconcluso sobre el trabajo no remunerado". Revista internacional del trabajo, Vol. 118, No 3, 1999. págs. 321-346.

${ }^{64}$ CASERO, V. y ANGULO, C., Una cuenta satélite de los hogares en España. 2003, Ed. INE, Madrid. 2008. Pág. 18.

${ }^{65} \mathrm{http}: / /$ www.fundaciontripartita.org/Recursos\%20digitales/Pages/BuscadorPublicaciones.aspx (consultado el 07/02/2019)

${ }^{66}$ En España más del sesenta por ciento de la población activa no cuenta con una acreditación reconocida de su cualificación profesional, además existe un volumen importante de aprendizaje no formal cuya falta de reconocimiento, en especial en colectivos como mujeres, inmigrantes, trabajadores desocupados, puede provocar situaciones de deficiente transición en el mercado laboral con el consiguiente riesgo de exclusión. http://www.mecd.gob.es/educa/incual/ice_recAcr.html (consultado el 13/03/2019) 
visibles en un contexto que no los reconoce. Por ello, insistimos que es necesario hacer visibles esos aprendizajes, incidiendo directamente en su reconocimiento y validación ${ }^{67}$.

\subsubsection{El Catalogo Nacional de Cualificaciones Profesionales y su relación con el sector estudiado}

Para delimitar el perfil de los trabajadores de bajo nivel de cualificación ${ }^{68}$ se utiliza el Catálogo Nacional de Cualificaciones Profesionales (en adelante CNCP) ${ }^{69}$, que ordena las cualificaciones profesionales susceptibles de reconocimiento $\mathrm{y}$ acreditación ${ }^{70}$, identificadas en el sistema productivo en función de las competencias apropiadas para el ejercicio profesional y constituye la base para elaborar la oferta formativa de los títulos y los certificados de profesionalidad ${ }^{71}$. En cualquier caso, la utilidad de la competencia profesional está en la capacidad de ésta para hacer frente a contextos profesionales cambiantes y en los que aspectos como la polivalencia y la flexibilidad son necesarios. Lo social complementa, como hemos constatado, en los componentes y ahora en su utilidad, lo individual ${ }^{72}$. En concreto, cualificaciones y ocupaciones seleccionadas que han sido tomadas de la Familia Profesional Servicios Socioculturales y a la Comunidad ${ }^{73}$.

En la actualidad, y sobre todo a partir de la Ley de las Cualificaciones y la Formación Profesional $^{74}$, la tendencia es a la integración de los subsistemas de formación y a la unificación de las ofertas formativas y sistemas de certificación y acreditación de las competencias. Para todo ello se articula el Sistema Nacional de las

\footnotetext{
${ }^{67}$ RUBIO HERRÁEZ, E., “Aprendizaje a lo largo de la vida. Vivir y trabajar en una Europa del conocimiento”, CEE Participación Educativa núm. 6, noviembre 2007, pág. 26.

${ }^{68}$ Son aquellos que poseen competencias en un conjunto reducido e actividades relativamente simples, siendo sus conocimientos teóricos y capacidades prácticas limitados. definición basada en la aportada por el Instituto Nacional de Cualificaciones (INCUAL).

69 Real Decreto 1128/2003, de 5 de septiembre, por el que se regula el Catálogo Nacional de Cualificaciones Profesionales. Real Decreto 1416/2005, de 25 de noviembre, por el que se modifica el Real Decreto 1128/2003, de 5 de septiembre, por el que se regula el Catálogo Nacional de Cualificaciones Profesionales (BOE de 3 de diciembre).

${ }^{70}$ REAL DECRETO 295/2004, de 20 de febrero, por el que se establecen determinadas cualificaciones profesionales que se incluyen en el Catálogo Nacional de Cualificaciones Profesionales, así como sus correspondientes módulos formativos que se incorporan al Catálogo Modular de Formación Profesional (BOE de 9 de marzo). REAL DECRETO 1087/2005, de 16 de septiembre, por el que se establecen nuevas cualificaciones profesionales, que se incluyen en el Catálogo Nacional de Cualificaciones Profesionales, así como sus correspondientes módulos formativos que se incorporan al Catálogo Modular de Formación Profesional, y se actualizan determinadas cualificaciones profesionales de las establecidas por el Real Decreto 295/2004, de 20 de febrero (BOE de 5 de octubre).

${ }^{71}$ BERMEJO GARCIA, L. La situación de los sistemas de..., op. cit., Informes Portal Mayores [Web de la revista] Año de publicación: 2006. Número 50. Pág. 20.

72 TEJADA FERNÁNDEZ, J. Acerca de las competencias profesionales $I$. Universidad de Barcelona. T, Herramientas 56. 1999. págs. 20-30.

${ }^{73}$ Las ocupaciones Asistente y cuidador de niños, Asistente y cuidador de mayores y Asistente y cuidador de personas con discapacidad se añadieron como ocupaciones propias de la cualificación, tras considerar lo establecido en el artículo 1.4 del Real Decreto 1424/85, que regula la relación del Servicio del Hogar Familiar. BOE núm. 193, de 13 de agosto de 1985.

${ }^{74}$ Ley Orgánica 5/2002, de 19 de junio, de las Cualificaciones y de la Formación Profesional de 20 de junio de 2002.
} 
Cualificaciones Profesionales a través del Instituto Nacional de las Cualificaciones (INCUAL) $^{75}$. Se genera el Catálogo Nacional de las Cualificaciones Profesionales ${ }^{76}$, donde a través de 26 familias profesionales, quedan integradas las cualificaciones profesionales de referencia para el empleo y la formación ${ }^{77}$.

Pero aun existiendo todo este conjunto de cualificaciones y perfiles profesionales, hay que considerar que no tenemos del todo resuelto ni el tema de la cualificación y menos aún la formación asociada, por lo que se necesita un mayor desarrollo de las mismas, en clave de un nuevo mapa competencial sobre este sector.

\subsubsection{El Sistema de cualificaciones y su relación con el sector estudiado}

El desarrollo de los Sistemas de cualificaciones responde al efecto combinado de una serie de factores económicos, sociales y políticos. Entre ellos cabe señalar la necesidad de orientar la formación y la cualificación de los trabajadores hacia las demandas del tejido productivo ${ }^{78}$, muchas veces poco definidas y atendidas en el marco de los sistemas educativos convencionales. De ese modo, se actúa sobre el capital humano, que es el recurso más importante de las empresas para la mejora sostenida de su competitividad y se mejoran las perspectivas de empleo de la población.

Por otro lado, también se debe destacar el reconocimiento de la experiencia laboral de aquellos que, por carecer de estudios relacionados con el sistema educativo, poseen un bajo o nulo nivel de titulación académica y, sin embargo, están altamente cualificados para el desempeño de una profesión u ocupación. Todo ello justifica la atención prestada y la necesidad de avanzar en el Sistema de cualificaciones español ${ }^{79}$.

Esencialmente, el punto de partida del Sistema tiene su origen en la observación y el estudio de las necesidades de cualificación que existen en el mercado, cualificaciones

\footnotetext{
75 En el Catálogo Nacional se establecen las competencias de referencia de cada una de las cualificaciones, se organiza por niveles de cualificación (de 1 a 5), integra y unifica los módulos formativos, a la vez que sirve referente para la evaluación y acreditación de las competencias profesionales adquiridas a través de la experiencia o por vías no formales de formación. En el nivel 1. Competencia en un conjunto reducido de actividades simples, dentro de procesos normalizados. Conocimientos y capacidades limitados. Competencia general: realizar las tareas de limpieza de superficies y mobiliario de la vivienda, de elaboración de alimentos, de lavado y planchado, cosido básico manual y preparado de camas, seleccionando y empleando las técnicas, útiles, productos y electrodomésticos para garantizar la higienización del domicilio y permitir la disponibilidad de uso de las camas, la ropa de hogar, las prendas de vestir y el consumo de alimentos, cumpliendo con la normativa de prevención de riesgos laborales.

${ }^{76}$ El Catálogo viene regulado por la primera norma publicada en desarrollo de la Ley 5/2002, que es el Real Decreto 1128/2003, de 5 de septiembre.

77 ALALUF, M. “La cualificación: ¿de qué se está hablando?”. op. cip., págs. 33-36.

78 De acuerdo con la Recomendación 195 de la OIT, sobre el desarrollo de los recursos humanos: educación, formación y aprendizaje permanente Conferencia General de la OIT. 2004, el término “cualificaciones” designa la expresión formal de las habilidades profesionales del trabajador, reconocidas en los planos internacional, nacional o sectorial.

${ }^{79}$ AMOR BRAVO, E.M. "Las cualificaciones profesionales: Un reto para los sistemas de educación y formación de la sociedad española”. Revista del Ministerio de Trabajo e Inmigración no 81. 2009. pág. 103.
} 
que pasan a integrarse en el nuevo CNCP, que sirve de referente tanto para la formación profesional integrada, como para la evaluación y acreditación de la competencia, tanto la adquirida por la experiencia laboral, como la que se obtiene a partir de cualquier aprendizaje no formal ${ }^{80}$.

Entendemos por tanto, que la extensión de los procesos de aprendizaje fuera del sistema educativo, que es uno de los rasgos básicos de la sociedad del conocimiento, tiene en el Sistema de cualificaciones profesionales, un referente básico que le proporciona coherencia y capacidad para avanzar. El papel de los agentes económicos y sociales en este proceso resulta fundamental, y desde luego, la iniciativa de los gobiernos regionales, que tienen amplias competencias en la materia, esencial para el éxito del modelo en su conjunto, ya que como hemos apuntado, existe una preocupación desde la propia normativa por una atención de calidad, la cual hay que aprovechar.

Hay que destacar en este punto, que el significado laboral de competencia como simple descripción de algo que debe ser capaz de hacer una persona que trabaje en una área laboral concreta y como una acción, conducta o resultado que la persona en cuestión debe poder realizar, se trata más bien de un punto de vista alternativo respecto del concepto de competencia, al considerar que el conocimiento, la comprensión de la situación, el discernimiento, y la acción inteligente, subyacen en la actuación y en la competencia; en otras palabras, la competencia supone transferencia como ya se ha indicado, respuesta a situaciones nuevas, valores humanos puestos en práctica, conocimiento técnico inteligente y desarrollo de las habilidades que sustentan su logro, lo que podría ser, según Pearson, (1984 citado en Elliott, 2000), un “conocimiento técnico inteligente" ${ }^{, 1}$.

Las competencias aparecen, en principio, relacionadas con los procesos productivos en las empresas, particularmente en el campo tecnológico, en donde el desarrollo del conocimiento ha sido muy acelerado. Éste es el contexto en el que nacen las denominadas competencias laborales, concepto que presenta varias definiciones, entre las que sobresale aquella que las describe como la capacidad efectiva para llevar a cabo exitosamente una actividad laboral plenamente identificada ${ }^{82}$.

Pero tal como está la situación en estos momentos, aún hay mucho camino por recorrer en tal dirección, por cuanto se evidencia una especial ausencia de cualificaciones profesionales vinculadas con los trabajos que consisten en la atención directa, ya que existe todo un conjunto de cualificaciones y perfiles profesionales en la atención a personas dependientes, hay que considerar que no tenemos del todo resuelto

\footnotetext{
${ }^{80}$ ALEX, L. Descripción y registro de las cualificaciones..., op. cit., págs.23-27.

${ }^{81}$ ELLIOTT, J. (2000). El cambio educativo desde la investigación-acción. Madrid. Ed. Morata. pág. 160.

82 IBERFOP-OEI, en HUERTA AMEZOLA, J., PÉREZ GARCÍA, I.S. y CASTELLANOS CASTELLANO, A.R. “Desarrollo curricular por competencias profesionales integrales”. Educar. 2000. pág. 2. http://www2.ufro.cl/docencia/documentos/Competencias.pdf (consultado el 07/02/2019).
} 
ni el tema de la cualificación y menos aún la formación asociada, y estamos necesitamos de mayor desarrollo de las mismas, en clave de un nuevo mapa competencial sobre los profesionales del sector, existiendo bastante desestructuración y desorganización en el ámbito formativo, existiendo como ya hemos anunciado, falta de reconocimiento profesional en este sector ${ }^{83}$.

\subsection{Las normas de competencias y su incidencia en el nuevo perfil profesional de las empleadas de hogar.}

Desde la perspectiva de las competencias laborales se reconoce que las cualidades de las personas para desempeñar de forma productiva en una situación de trabajo, no sólo depende de las situaciones de aprendizaje escolar formal, sino también del aprendizaje derivado de la experiencia en situaciones concretas de trabajo. Por lo mismo, la propuesta se concreta en el establecimiento de las normas de competencia, estas son el referente y el criterio para comprobar la preparación de un individuo para un trabajo específico. Las normas de competencia se conciben como una expectativa de desempeño en el lugar de trabajo, referente que hace posible comparar un comportamiento esperado. De este modo, la norma constituye un patrón que permite establecer si un trabajador es competente o no, independientemente de la forma en que la competencia haya sido adquirida ${ }^{84}$.

Según el Servicio Público de Empleo Estatal ${ }^{85}$, “...las competencias definen el ejercicio eficaz de las capacidades que permiten desarrollar una ocupación profesional con respecto a los niveles que requiere la tarea”, siendo por tanto algo más que el conocimiento técnico que hace referencia al saber y al saber hacer. En este sentido, "El concepto de competencia ${ }^{86}$ no sólo engloba las capacidades requeridas para el ejercicio de una actividad profesional, sino también las requeridas para el conjunto de comportamientos, capacidad de análisis, toma de decisiones, transmisión de información, etc., que se consideran necesarias para el pleno desarrollo de la tarea” ${ }^{87}$. Con todo ello podemos observar, el concepto de competencia engloba no sólo las capacidades requeridas para el ejercicio de una actividad profesional, sino también un conjunto de comportamientos, facultad de análisis, toma de decisiones,

\footnotetext{
${ }^{83}$ TEJADA FERNÁNDEZ, J., "Perfiles profesionales en la atención a personas dependientes. op.cit. págs. 69-84.

${ }_{84}^{84}$ LÉVY-LEBOYER, C., Gestión de las competencias: cómo analizarlas, cómo evaluarlas, cómo desarrollarlas. Barcelona, Ediciones Gestión 2000. 1997, pág. 43.

${ }^{85}$ Antiguo Instituto Nacional de Empleo en España. INEM. 1995.

${ }^{86}$ En el Real Decreto 676/1993 de 7 de mayo, por el que se establecen directrices generales sobre los títulos y las correspondientes enseñanzas mínimas de formación profesional (BOE del 22 de mayo), define la competencia profesional como "conjunto de conocimientos, habilidades, destrezas y actitudes, adquiridos a través de procesos formativos o de la experiencia laboral, que permiten desarrollar y realizar roles y situaciones laborales requeridos en el trabajo".

${ }^{87}$ http://blog.infojobs.net/archives/0000/0014/Presentacion_OBSERVATORIO_DE_COMPETENCIAS. PDF http://www.observal.es/ (consultado el 07/02/2019).
} 
transmisión de información, considerados necesarios para el pleno desempeño de la ocupación.

La competencia, por tanto, es como un conjunto de conocimientos prácticos socialmente establecidos; habrá que señalar que dichos conocimientos no se refieren a meros quehaceres rutinarios, sino que reflejan el desarrollo de determinadas habilidades, desarrollando además estrategias que le permiten utilizarlos creativamente frente a las diversas situaciones que lo demandan, destacando así que lo que se aprende es la competencia, no las realizaciones particulares ${ }^{88}$.

Las labores domésticas se engloban perfectamente en esta definición de competencias, porque sus actividades pueden ser tan complejas y variadas como el trabajo de cualquier obrero, y aún más importantes cuando van enfocadas al aspecto humano de las labores domésticas, como pueden ser el cuidado de niños o ancianos, para lo que se desarrollan distintas aptitudes, habilidades y actitudes para poder realizar estas tareas de forma satisfactoria, por tanto, si consideramos que profesionalizar significa otorgar a los trabajadores de un determinado sector unos derechos laborales y de protección social equivalentes a aquellos de los que disfrutan el resto de los trabajadores, quizá solo podrá ser posible profesionalizar el sector del trabajo doméstico y los cuidados si se combinan fondos públicos, sociales y los privados por parte de los empleadores, ya que se trata de una economía familiar.

\subsubsection{Delimitación del necesario perfil de competencias en este sector}

Como se ha podido constatar, no existe una única definición normativa, en todas las definiciones que hacen referencia a las competencias encontramos varios elementos comunes, como que integran capacidades, habilidades, conocimientos, actitudes o aptitudes, así como que están vinculadas con el desarrollo de una actividad o tarea y por último que el contexto es clave para su constatación. Por ello, debemos indicar aquí, que con las competencias es posible determinar los requisitos de un puesto de trabajo de forma global (no únicamente respecto a conocimientos) y, además, es posible evaluar a las personas estableciendo un perfil de competencias determinado.

Por un lado, es posible establecer qué competencias son necesarias para un puesto de trabajo con aplicación directa en términos de ocupación y formación y, por otro,

\footnotetext{
${ }^{88}$ En palabras de Leonard Mertens, para el Centro Interamericano de Investigación y Documentación sobre Formación Profesional "La competencia laboral debe interpretarse como un movimiento que pretende ser una respuesta innovadora para administrar y regular el mercado de trabajo interno y externo de la empresa ante las transformaciones del mundo de la producción que en la actualidad se presentan. Las principales características de esa transformación son la aplicación de sistemas de innovación abiertos, complejos y dinámicos, que obligan a reformular la relación entre la educación formación y el trabajo, en dos sentidos. Por una parte demandan un "saber hacer" del personal, y especialmente del operario, basado en diferentes y muchas veces mayores conocimientos, habilidades y actitudes que en el pasado. Por otra parte, este "saber hacer" se encuentra inmerso en una modificación continua debido a los cambios incesantes del proceso de trabajo". MERTENS, L. Competencia laboral: sistemas, surgimiento y modelos. Montevideo: Cinterfor, 1996. págs. 115-119. http://www.oei.es/etp/competencia_laboral_sistemas_modelos_mertens.pdf (consultado el 09/02/2019)
} 
aporta al trabajador aspectos como el reconocimiento de la experiencia o la formación a lo largo de la vida a través de la certificación o calificación de competencias ${ }^{89}$.

La adecuación entre el perfil de competencias del puesto de trabajo y el trabajador pasará a ser el factor clave para desarrollar con éxito la actividad profesional. En este punto es importante destacar que, debido a la naturaleza del concepto, tal y como hemos advertido ya, las competencias de las que dispone una persona no son inalterables, sino que pueden modificarse con la formación, la experiencia, etc., por lo que el proceso de esta formación permanece durante todo el periodo de su vida laboral activa.

Por consiguiente, nos encontramos en un tiempo en el que la formación se ha convertido en un factor clave para superar la situación económica actual y se requiere, más que nunca, una preparación para llegar a ser globalmente competitivos y poder aumentar la capacidad de empleo de las personas en situación de desempleo, las competencias profesionales encuentran respuesta a su máxima potencialidad.

En cuanto a las competencias y tareas más importantes a desempeñar por parte de ésta relación laboral especial, resaltan por un lado, las propias del ámbito profesional como son limpieza, cocina, planchado etc. y tareas de otra índole como el cuidado de niños, personas mayores y discapacitados, que aunque reconocidas como competencias propias, los expertos ven en ellas la posibilidad de mejorar sus condiciones laborales y favorecer la empleabilidad a través de su acreditación y certificación ${ }^{90}$.

\section{Conclusiones y propuestas}

Primera.- Uno de los factores que influye y dificulta la profesionalización y que a la vez las personas trabajadoras de este sector sean consideradas "profesionales" que prestan servicios y no meras "servidoras", es la falta de reconocimiento de las cualificaciones que requieren muchas de estas actividades, cualificaciones que además favorecerían el reconocimiento social de ésta actividad y de sus trabajadoras.

Y todo ello porque el servicio doméstico y los cuidados personales son actividades caracterizadas por el papel predominante de la interacción personal y la cercanía entre quien recibe el servicio y el que lo presta. La convivencia tan directa entre empleador y trabajadora, a menudo genera lazos afectivos que hacen que el trabajo doméstico sea concebido como algo más cercano al hogar que al mercado laboral y correspondiente más al ámbito privado que al ámbito profesional, esto se traducen en un "trato familiar" en ocasiones con una fuerte connotación servil, que hace complicado establecer el límite en el tiempo y el tipo de trabajo ya que la relación, entre otras cosas, se basa en aspectos diferentes al laboral, como son el afecto que hacen que la relación laboral sea ambigua negando en ocasiones al trabajo desempeñado el status de "trabajo profesional”.

Segunda.- Las trabajadoras del empleo doméstico presentan necesidades formativas de distinta índole, encontrándonos con distintos tipos de trabajo dentro del

89 DINAMIA (2008). Conclusiones y Recomendaciones..., op. cit., Dinamia.org (consultado 30/01/2019).

${ }^{90}$ FUNDACIÓN GLOBALIA: Detección de necesidades formativas de trabajadores/as para la atención a la dependencia y mecanismos para el fomento de la formación continua, 2008. 
sector: un empleo profesional y bien formado, o la contratación de personas "no profesionales”, al carecer de la formación formal específica en este campo, se hace a través del empleo doméstico y el trabajo que realizan suele implicar tanto tareas concretas de cuidado como tareas domésticas, y por último el cuidado familiar tradicional, que como sabemos no es asalariado.

Tercera.- Para que la prestación de servicios quede incluida en el campo de aplicación de la Seguridad social, la misma ha de tener un mínimo de profesionalidad, en la medida en que se permite que el Gobierno puedan excluir del campo de aplicación del Régimen correspondiente de la Seguridad Social, a las personas cuyo trabajo por cuenta ajena, en atención a su jornada o a su retribución, pueda considerarse marginal y no constitutivo de medio fundamental de vida. Aunque nos parezca desalentador, la realidad es que pasa a menudo, porque en el caso de estas trabajadoras, se han tenido como práctica habitual, considerar su sector como marginal, por ello ni se plantean que su trabajo puede llegar a ser profesional.

Cuarta.- Sería aconsejable, que toda competencia profesional fuese analizada en relación con la totalidad de su actividad o modo de actuación y no como la suma matemática de los análisis de actividades o tareas parciales e independientes. Existen unas funciones básicas que tiene que desarrollar el trabajador, en cada una de estas funciones esenciales es necesario definir el conjunto de problemas que el trabajador debe ser capaz de identificar, analizar y resolver. Por esta misma razón, el enfoque basado en competencias es estratégico en la medida que hace posible gestionar cambios cualitativos en la competitividad ya que las competencias surgen para dar una respuesta a una situación laboral altamente cambiante. Una situación variable, que cada vez más, requiere profesionales formados y con unas características determinadas que favorezcan la adaptación rápida

Quinta.- Sería posible establecer qué competencias son necesarias para un puesto de trabajo con aplicación directa en términos de ocupación y formación y, por otro, aporta al trabajador aspectos como el reconocimiento de la experiencia o la formación a lo largo de la vida a través de la certificación o calificación de competencias. Se advierte por tanto, que la adecuación entre el perfil de competencias del puesto de trabajo y el trabajador pasará a ser el factor clave para desarrollar con éxito la actividad profesional.

Sexta.- La identificación de competencias laborales permite establecer las funciones y tareas que implica el desempeño profesional. A partir de ello se pueden determinar cuáles son los conocimientos, habilidades y aptitudes que se requieren para lograr dicho desempeño. Precisamente, la principal debilidad que aqueja al servicio doméstico son sus bajos niveles de profesionalización, donde la necesidad creciente de cuidado y atención a nuestros mayores continúa prestándose, o bien en el interior de los hogares (por familiares, básicamente mujeres), o saliendo al mercado para ser cubierto por personal no especializado. Ha de considerarse, en este sentido, la falta de solvencia de la demanda, circunstancia que termina traduciéndose en una generación de empleo precario, con tasas de temporalidad, trabajo a tiempo parcial y subempleo bastantes más 
elevadas que en el conjunto de la economía, ocupado por personas con bajos niveles educativos y con un claro predominio de población extranjera.

\section{BIBLIOGRAFÍA}

ALALUF, M. “La cualificación: ¿de qué se está hablando?”. Revista Europea de Formación Profesional núm. 2, Bruselas, 1991.

ALEX, L. (1991). “Descripción y registro de las cualificaciones”. Revista Europea de Formación Profesional, nº 2. CEDEFOP, Berlín.

AMOR BRAVO, E.M. "Las cualificaciones profesionales: Un reto para los sistemas de educación y formación de la sociedad española”. Revista del Ministerio de Trabajo e Inmigración $\mathrm{n}^{\circ}$ 81. 2009.

APARICIO RUIZ, M.G., La profesionalización de los empleados al servicio del hogar familiar (desde el contraste comparado de la normativa francesa), Ed. EOLAS EDICIONES, 2014.

ARAGÓN MEDINA, J., CRUCES AGUILERA, J., y ROCHA SÁNCHEZ, F. Las condiciones laborales en el sector de atención a la dependencia: una aproximación de calidad en el empleo. 2008. Fundación $1^{\circ}$ de Mayo. Documento de Trabajo 2/2008.

BAYLOS GRAU, A. "La carrera profesional del trabajador: promoción y ascensos en el Derecho del Trabajo”. Revista Documentación Administrativa, 210/211. 1987.

BERMEJO GARCIA, L., "La situación de los sistemas de formación y de cualificación de las ocupaciones en la atención a mayores dependientes. Propuestas de avance en la elaboración de perfiles ocupacionales y en la formación por competencias”. Madrid, portal mayores, informes portal mayores nº50. 2006.

CACHON RODRIGUEZ, L., "La formación y los "nuevos yacimientos de empleo” en España”. Reis: Revista española de investigaciones sociológicas, núm. 77-78.

CASERO, V. y ANGULO, C., Una cuenta satélite de los hogares en España. 2003, Ed. INE, Madrid. 2008.

CASTIÑEIRA FERNANDEZ, J., "La tutela de la profesionalidad del trabajador, la formación y readaptación profesionales y el estatuto de los trabajadores”. RPS, 121, 1979.

CRESPO LÓPEZ, M. Y LÓPEZ MARTÍNEZ, J.: El apoyo a los cuidadores de familiares mayores dependientes en el hogar: desarrollo del programa Cómo mantener su bienestar. Ministerio de Trabajo y Asuntos Sociales. IMSERSO, 2007. 
CRUZ, P. K., y VEGA, G. M.: La gestión por competencias: una nueva herramienta en la planificación estratégica del recurso humano, Antofagasta, Ed. Universidad de Antofagasta, 2001.

CUEVA PUENTE, C., La relación laboral especial de los empleados de hogar. Lex Nova, 2005.

DELCOURT, J.: Nuevas presiones a favor de la formación en la empresa, Formación Profesional, (17), 3-14, 1999.

DE LA FUENTE, J. "Estrategias metodológicas y de evaluación para promover la competencia para aprender a aprender”. Aula de Innovación Educativa nº 192 (junio 2010).

DE LUCAS, J., “¿Elogio de Babel? Sobre las dificultades del Derecho frente al proyecto intercultural”. ACFS, n³1, 1994.

D'IRIBARNE, A. (1996): "Una lectura para los paradigmas del Libro blanco sobre la educación y la formación”, Revista europea de formación profesional, 8-9.

ELLIOTT, J. (2000). El cambio educativo desde la investigación-acción. Madrid. Ed. Morata.

ERTL, H. y PHILLIPS, D. "Standardization in EU education and training policy: findings from a European research network”. Comparative Education, 42 (1), 2006.

ESPARZA CATALÁN, C. Discapacidad y dependencia en España. Madrid, Informes Portal Mayores, nº 108. 2011.

GALLART FERNÁNDEZ-PUEBLA, A., Sobrecarga del cuidador inmigrante no profesional formal en Barcelona. Ed. Universitat Internacional de Catalunya, 2007. Instituto de la Mujer: Cuidados a personas dependientes prestados por mujeres: valoración económica, 2008.

GONZÁLEZ ORTEGA, S., director de la investigación; Margarita Arenas Viruez y otros, $1^{\mathrm{a}}$ ed. Madrid. Consejo Económico y Social (España). 2013.

GOMEZ LLORENTE, L. "El Aprendizaje a lo Largo de Toda la Vida. En Aprender a lo largo de la vida”. Participación Educativa nº 9. noviembre 2008.

HUERTA AMEZOLA, J., PÉREZ GARCÍA, I.S. y CASTELLANOS CASTELLANO, A.R. "Desarrollo curricular por competencias profesionales integrales". Educar. 2000.

LABRUFFE, A., La gestión de competencias: planteamientos básicos, prácticas y cuadros de mando. Madrid: Ed. AENOR. 2008.

LÉVY-LEBOYER, C., Gestión de las competencias: cómo analizarlas, cómo evaluarlas, cómo desarrollarlas. Barcelona, Ediciones Gestión 2000. 1997. 
MARTÍN ORTEGA, E. (2008): “Aprender a aprender: clave para el aprendizaje a lo largo de la vida”. En Participación Educativa, núm. 9 (revista del Consejo Escolar del Estado), noviembre 2008.

MARY NASH. A., "20 años de Historia de las Mujeres”. Arenal: Revista de historia de mujeres, Vol. 20, nº $1,2013$.

MERTENS, L. Competencia laboral: sistemas, surgimiento y modelos. Montevideo: Cinterfor, 1996.

MONTOYA MELGAR, A. La protección de las personas dependientes. Ed. Civitas. 2007.

PEREZ-ESPINOSA SÁNCHEZ, F. "Organización del trabajo, sistema de clasificación en categorías y defensa de la profesionalidad del trabajador”. Lecciones de Derecho del Trabajo, Universidad Complutense, Madrid, 1980.

ROQUETA BUJ, R., La protección de la dependencia, comentarios a la ley 39/2006, de 14 de diciembre, de promoción de la autonomía personal y atención a las personas en situación de dependencia, Ed. Tirant lo Blanch, Valencia, 2007.

RUBIO HERRÁEZ, E., “Aprendizaje a lo largo de la vida. Vivir y trabajar en una Europa del conocimiento”, CEE Participación Educativa núm. 6, noviembre 2007.

SARASÚA GARCÍA, C., Criados, nodrizas y amos: El servicio doméstico en la formación del mercado de trabajo madrileño, 1758-1868. Editorial: Siglo XXI de España Editores, S.A., 1994.

TEJADA FERNÁNDEZ, J., “Perfiles profesionales en la atención a personas dependientes. Una mirada desde la formación”. Revista de Educación Inclusiva, Vol. 2, $\mathrm{N}^{\circ} .2,2009$.

TEJADA FERNÁNDEZ, J. Acerca de las competencias profesionales $I$. Universidad de Barcelona. T, Herramientas 56. 1999.

VALDÉS DE LA VEGA, B., La profesionalidad del trabajador en el contrato laboral. Ed. Trotta. 1997.

VÁZQUEZ, J.M., El servicio doméstico en España. Su situación real y propuesta de resolución para sus problemas, Madrid, Ed. Instituto Nacional de Previsión, Serie Estudios Premio Marvá, 1960. 